\title{
Erratum to: The impact of zoning regulations on thermal comfort in non-conditioned housing in hot, humid climates: findings from Dhaka, Bangladesh
}

\author{
Saiful Islam • Shannon Van Zandt
}

Published online: 11 October 2013

(C) Springer Science+Business Media Dordrecht 2013

\section{Erratum to: J Hous and the Built Environ DOI 10.1007/s10901-013-9373-2}

The original article has been published incorrectly with an error in the author name. The corrected version is given in the erratum.

The online version of the original article can be found under doi:10.1007/s10901-013-9373-2.

S. Islam

Ahsanullah University of Science and Technology, Dhaka, Bangladesh e-mail: saif_1509@yahoo.com

S. Van Zandt $(\bowtie)$

Texas A\&M University, MS 3137 TAMU, College Station, TX 77843-3137, USA

e-mail: svanzandt@arch.tamu.edu 